\title{
Inkjet Printed Multi-Walled Carbon Nanotube Sensor for the Detection of Lead in Drinking Water
}

\author{
${ }^{1}$ Connor Rahm, ${ }^{2}$ Fernando Torres-Canas, ${ }^{1}$ Pankaj Gupta, ${ }^{2}$ Phillip Poulin, ${ }^{1}$ Noe Alvarez \\ ${ }^{1}$ Department of Chemistry, University of Cincinnati, Cincinnati, Ohio, 45221-0172, United \\ States \\ ${ }^{2}$ University of Bordeaux, UMR5031, 33600 Pessac, France
}

\begin{abstract}
The detection of $\mathrm{Pb}^{2+}$ was performed using a completely inkjet printed multi-walled carbon nanotube (IJP-MWNT) sensor employing anodic stripping voltammetry (ASV) using Osteryoung square wave stripping voltammetry (OSWV) as the detection step. The MWNT ink was prepared in water using bile salts (BS) as a surfactant, which was further washed out with DI water and then remaining MWNT was used as an electrode surface. The IJP-MWNT electrode was used as the working electrode with a platinum wire and glass capillary $\mathrm{Ag} / \mathrm{AgCl}$ as auxiliary and reference electrode, respectively. The electrode was optimized in $0.1 \mathrm{M}$ acetate buffer $(\mathrm{pH}=$ 4.3) and had a linear range of $5-50 \mathrm{ppb}\left(\mathrm{R}^{2}=0.98235\right)$ a sensitivity of $20.15 \mathrm{nA} / \mathrm{ppb}$ and a limit of detection (LOD) of $1.632 \mathrm{ppb}$ for $\mathrm{Pb}^{2+}$. The analytical applicability of electrode was tested in a real drinking water sample (i.e.) Cincinnati tap water with a linear range of $15-70 \mathrm{ppb}\left(\mathrm{R}^{2}=\right.$ 0.98752 ) a sensitivity of $2.654 \mathrm{nA} / \mathrm{ppb}$ and a LOD of $1.269 \mathrm{ppb}$ for $\mathrm{Pb}^{2+}$.
\end{abstract}

Key word: Inkjet printed multi-walled carbon nanotubes, lead, stripping voltammetry, drinking water 


\section{Introduction}

Society has known about the adverse health effects of lead exposure in humans since the ancient Roman empire over 2000 years ago. ${ }^{1}$ At low levels, lead can damage the human central nervous system, liver, kidney, and cardiovascular system and cause physiological and neurological problems in developing children who are most susceptible to lead poisoning. ${ }^{2}$ Lead has a long biological half-life in humans causing symptoms such as stress, headaches, and further leads to the risk of infertility and birth defects. ${ }^{3}$ Lead in drinking water is currently regulated in the United States by the Environmental Protection Agency (EPA) with a maximum contamination level (MCL) of $15 \mathrm{ppb}$ and the World Health Organizations (WHO) with a MCL of $10 \mathrm{ppb}$ of lead. ${ }^{4,5}$ There are reports of lead contamination in drinking water greater than the WHO's MCL across the globe. Researchers have reported; Canadian schools with lead levels as high as 45 ppb, French metropolitan homes exposing 139,000 children of ages 6 months to 6 years to over 10 ppb lead, Hong Kong's public rental housing high rises, the National Taiwan University Campus, and here across the US toxic lead levels in drinking water. ${ }^{6-10}$

The gold standard for the analytical detection lead in water samples are inductively coupled plasma mass spectroscopy (ICP-MS), and atomic adsorption spectroscopy (AAS). The down fall of the techniques are they required sample preparation steps, and a certified lab with proper equipment and personal. Both instruments are expensive and require consistent maintenance and cleaning for obtaining accurate results. One parallel observation throughout each report was that a specific end source (faucet) of water could give different results depending on sampling technique, water quality of the sample and time sample was taken. Tap water chemistry is ever changing and adds another challenge to lead detection. The solubility of lead in tap water pipes can change depending on $\mathrm{pH}$, alkalinity, hardness, temperature, chlorine to sulfate mass ratio, 
dissolved oxygen, natural organic matter, and flow rate of water. ${ }^{11}$ Cartier et.al report that $48 \%$ of total lead found in copper drinking water pipes is due to solder, brass couplings and nipples and are a large source of particulate lead. ${ }^{12}$ Due to the constant changing of the water chemistry and use at a single tap a point of care (POC) devise is needed. ICP-MS and AAS are not portable and require time for lab processing which make them the non-ideal instrument for the detection at POC. That is where electrochemical techniques can overcome the need for real-time, accurate, and high number of sample processing.

Electrochemical techniques employed directly at the source of water consumption are possible with portable sensors and devices. Chałupniak et.al have demonstrated an adsorption based microfluidic lab-on-a-chip (LOC) sensor that has a Limit of detection (LOD) of $0.5 \mathrm{ppb} \mathrm{Pb}^{2+} .13$ Lin et.al have implemented an inexpensive long-term four electrode impedance based electrical sensors. ${ }^{14}$ Xuan et.al fabricated a micro-patterned reduced graphene-oxide heavy metal sensor,

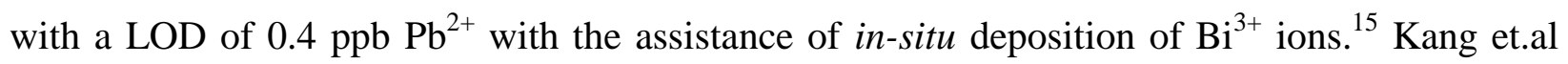
have demonstrated a low cost copper sensor with a LOD of $4.4 \mathrm{ppb} \mathrm{Pb}^{2+}$ using ASV in acetate buffer. ${ }^{16}$ Anodic stripping voltammetry has been explored extensively for the detection of heavy metals at many different electrode surfaces. Many materials have been adopted as electrodes for heavy metal detection using ASV, such as the mercury drop and mercury film electrodes ${ }^{17,18}$, bulk bismuth and bismuth film electrodes ${ }^{19-22}$, an antimony film electrode ${ }^{23}$, a boron doped diamond electrode ${ }^{24}$, carbon nanotube modified and fiber electrodes ${ }^{25-29}$, and simultaneous use of $\mathrm{Hg}, \mathrm{Au}, \mathrm{Pt}, \mathrm{C}$, and $\mathrm{Ag}$ electrodes arrays ${ }^{30}$. The use of mercury as an electrode material has been abandoned due to its toxicity. Although, bismuth has been a great substitute for mercury it adds complexity to the pre-concentration step and has a smaller potential window. Film electrodes need to be continually renewed, and boron doped diamond electrodes have a tendency 
of fouling. The use of noble metals also has restricted potential windows and are expensive, while carbon nanotubes have been shown to have large potential windows, combat fouling, large surface area, and are largely inert to electrical potentials having long lifetimes as electrodes. ${ }^{31}$

Printed electrode fabrication can be manufactured at high production rates and cheap costs to fabricate sensors that can be bought and used at POC. Two common types of printed electrodes are inkjet printed, and electronic flat screen-printed electrodes. The advantages of printing electrodes are high reproducibility between samples, high production rate, and low-cost fabrication. ${ }^{32}$ There have been many types of screen-printed carbon electrodes (SPCE), mercury film SPCE, ${ }^{33}$ bismuth film SPCE, ${ }^{34,35}$ gold film SPCE, ${ }^{36}$ and other modified SPCE $, 22,37$ and most have detection limits in low ppb levels of lead. Ultimately, screen printed electrodes are made for single use detection and lose their electrochemical sensitivity with continued usage. The ink material for many screen-printed electrodes is amorphous carbon, formulated with graphite or carbon black using organic binders and solvents. The inks use binders and organic solvents due to the inks need to maintain a certain viscosity and composition for printing.

There have been inkjet printed electrode reported on electrochemical determinations but very few of them are reported on heavy metal detection ${ }^{38}$ Xiao et. al. have prepared a sandwiched structured ionic liquid carbon nanotube graphene film produced by inkjet printing, with the addition of $\mathrm{Bi}^{3+}$ ions creating a bismuth film giving a LOD of $0.0414 \mathrm{ppb}(0.2 \mathrm{nM}) \mathrm{Pb}^{2+} \cdot{ }^{39}$ Inkjet printed electrodes have been used as resistance based ammonia gas sensors. ${ }^{40,41}$ Lee et. al. have demonstrated the application of a jet printed CNT electrode for the detection of dopamine. ${ }^{42}$ Schneider et. al. have jet printed gold nanoparticle ink with silver to create a sensor for the detection of sulphur dioxide in wine. ${ }^{43}$ The advantages of inkjet printing are the ease of design, the variety of material as precursors for the ink, the repeatability between prints, and control over 
printed film thickness, width, geometry and concentration. ${ }^{44,45}$ Another advantage is the ease of printing CNTs dissolved in water using bile salts as a surfactant that can be easily washed away with water, leaving CNTs free of binders and organic solvents. In most cases the CNTs are used as purchased with no further purification. The printed CNT electrodes can be annealed and washed until there are little to no impurities left behind ${ }^{44}$ Carbon nanotubes are a great electrode material due their great electrical conductivity, high aspect ratio, chemical inertness, and have been shown to greatly enhance sensor applications. ${ }^{37,46-50}$

Herein, we present work on an inkjet printed multi-walled carbon nanotube (IJP-MWNT) electrode as sensor for the trace detection of lead. The active surface of the sensor is the MWNTs and printed underneath is a conductive silver track. Giving the sensor the sensitivity needed to detect trace levels of lead. The carbon nanotube electrode surface provides a high surface area that is unchanging during the testing process which can withstand the applied electrical potential without changing the electrode surface overtime. Osteryoung square wave voltammetry was used as the detection waveform. ${ }^{51}$ The IJP-MWNT based sensor was first optimized in acetate buffer for the detection of $\mathrm{Pb}^{2+}$. For the best of our knowledge, this is the first time reported in literature that the combination of inkjet printed silver tracks and pure MWNTs have been used for the trace detection of $\mathrm{Pb}^{2+}$ in drinking water.

\section{Experimental Section}

\subsection{Chemicals}

Chemicals $\mathrm{Pb}\left(\mathrm{NO}_{3}\right)_{2} \quad(\geq 99.99 \%), \quad \mathrm{Cd}\left(\mathrm{NO}_{3}\right)_{2} \quad(\geq 99.99 \%), \quad \mathrm{Cu}\left(\mathrm{NO}_{3}\right)_{2} \cdot \mathrm{H}_{2} \mathrm{O} \quad(\geq 99.99 \%)$ were purchased from sigma Aldrich, $\mathrm{NaOAc} \cdot 3 \mathrm{H}_{2} \mathrm{O}(\geq 99.0 \%)$ and $\mathrm{CH}_{3} \mathrm{COOH}(\geq 99.0 \%)$ was purchased from Fisher Scientific, $\mathrm{K}_{3}\left[\mathrm{Fe}(\mathrm{CN})_{6}\right](\geq 99.0 \%)$ was purchased from J.T Baker Chem. 
Co. and silver ink CI-1001 was purchased from Engineered Material Systems. MWNTs were purchased from ELICARB, prepared by the method of chemical vapor deposition (CVD) without any modification and with a purity of $70-90 \%$. Bile salts surfactant (a mixture of 50/50 wt $\%$ of sodium cholate and sodium deoxycholate) were purchased from Fluka. Fast drying silver paint was purchased from Ted Pella. All Chemicals were used as received without further purification. Deionized water (Nanopure water purification system) were used for preparing all solutions. The working solution were all prepared with $0.1 \mathrm{M}$ acetate buffer $\mathrm{pH}$ 4.3. Stock solution of each

analyte $\mathrm{Pb}^{2+}, \mathrm{Cd}^{2+}$, and $\mathrm{Cu}^{2+}$ were made by diluting the appropriate amount of their salts in deionized water.

\subsection{Instrumentation}

All electrochemical data were collected on a $\mathrm{CH}$ Instrument Electrochemical Workstation connected to a single compartment three-electrode cell. Scanning electron micrographs (SEMs) were obtained on a FEI XL30 ESEM (Philips). The optical images were obtained on a digital microscope (Keyence, VHX-2000). Raman spectra were collected using a Renishaw in Via Raman microscope system, excited by a 514nm Ar-ion laser.

\subsection{MWNT Ink Preparation}

The dispersion was carried out using $1 \mathrm{wt} \%$ of MWNT and $1 \mathrm{wt} \%$ of bile salts (BS) in $15 \mathrm{~mL}$ of freshly deionized water. The mixture was tip-sonicated (Branson Sonifier 250 ultrasonicator) for 30 minutes at $20 \%$ power and delivering pulses of $1 \mathrm{~s}$ separated by $1 \mathrm{~s}$ intervals of silence. The dispersion was placed in an ice bath to prevent overheating. The dispersion was then centrifuged at $2200 \mathrm{~g}$ for 30 minutes in order to remove large aggregates and not dispersed MWNT. Finally, 
the suspension was mixed with $10 \%$ of ethylene glycol to prevent the formation of the coffee ring during the printing process.

\subsection{Inkjet Printing of MWNT}

All electrodes were printed using a "Microdrop Technologies" printer with a nozzle size of 70 $\mu \mathrm{m}$. Printing was controlled by a piezoelectric actuator. The piezo voltage (between 95 and 105 V), pulse duration (between 22 and $25 \mu \mathrm{s}$ ) and the printing frequency (100 Hz) were adjusted to obtain jetting of single droplets with a volume of $\approx 310 \mathrm{pL}$ before printing the electrode. The temperature of the plate was set at $70{ }^{\circ} \mathrm{C}$ to promote fast drying while the nozzle temperature was kept at $20^{\circ} \mathrm{C}$. All inks were filtered $(5 \mu \mathrm{m})$ before printing. The electrode printing process is shown in (Fig. 1).The printed electrode is described as follows: a single line $(50 \mathrm{~mm})$ of silver ink was printed on the polyethylene naphthalate (PEN) substrate using a drop distance of $100 \mu \mathrm{m}$, followed by an annealing process in vacuum at $100^{\circ} \mathrm{C}$ overnight. Then, MWNT ink was printed on the top of each silver track with the repetitive 10 passages of MWNT ink. We made sure that the entire silver track was completely covered by the MWNT. Finally, the electrode line was annealed at $100^{\circ} \mathrm{C}$ under vacuum overnight. In order to remove the surfactant, the printed sensors were washed by dipping them in a water tank for $24 \mathrm{~h}$, and by subsequently annealing them at $100{ }^{\circ} \mathrm{C}$ in vacuum for $1 \mathrm{~h}$. It was observed that the structural integration of the electrode line remained unchanged when the washing process was performed. 


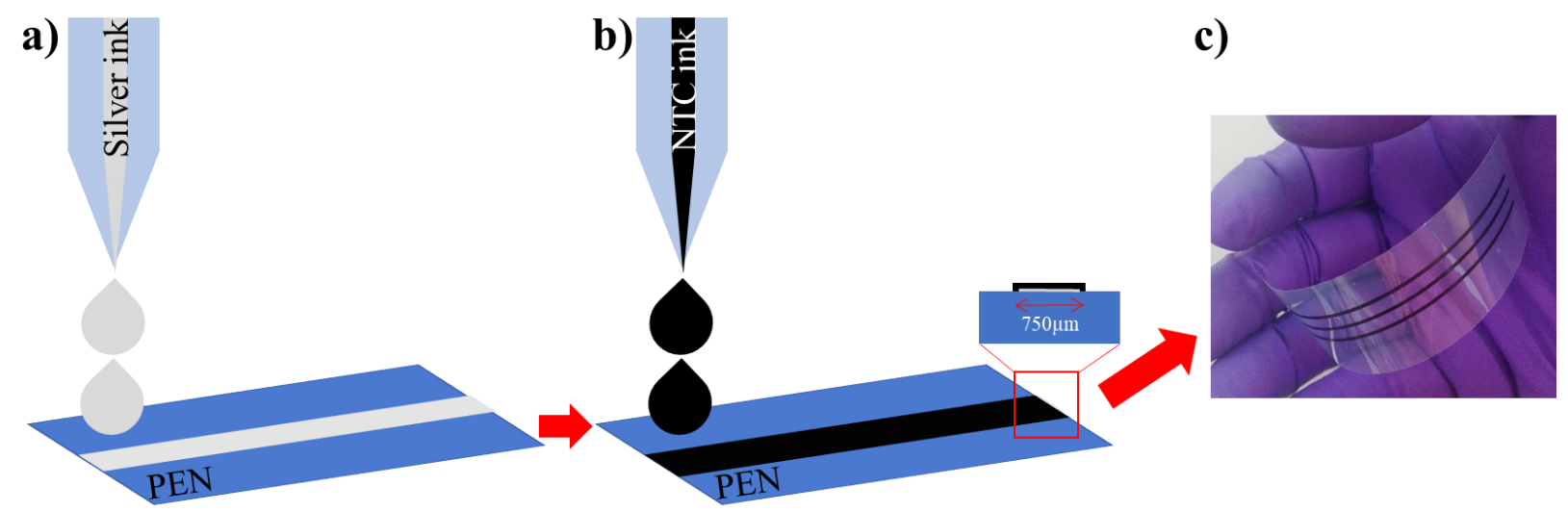

Fig.1. a) Printing of silver track, b) printing of MWNT ink completely covering silver and c) image of flexible IJP-MWNT electrode.

\subsection{Preparation of IJP-MWNT Electrode}

Copper wire leads were connected to $5 \mathrm{~mm}$ length of the IJP-MWNT electrode surface using fast drying silver paint. The silver paint was annealed in an oven at $45^{\circ} \mathrm{C}$ for 30 minutes to ensure solvent evaporation. The silver paint and tip of the electrode were covered with a UV-cured insulating polymer, leaving only the MWNT electrode bare as the electrode surface. Different electrode lengths of $20 \mathrm{~mm}, 10 \mathrm{~mm}, 5 \mathrm{~mm}$, and $2 \mathrm{~mm}$ were explored.

\subsection{Electrochemical Technique}

All electrochemical testing was performed in $0.1 \mathrm{M}$ acetate buffer $(\mathrm{pH} 4.3)$ electrolyte solution unless otherwise mentioned. A glass frit capillary encased $\mathrm{Ag} / \mathrm{AgCl}$ wire in $3.0 \mathrm{M} \mathrm{NaCl}$, and solid Pt wire were used as the reference and auxiliary electrodes respectively for all testing. The IJP-MWNT electrode was first characterized by cyclic voltammetry in $2 \mathrm{mM}$ hexaamineruthinium (III) chloride. Anodic stripping voltammetry was used for the trace detection of the heavy metal ion $\mathrm{Pb}^{2+}$. The Osteryoung square wave waveform, was used during the detection step of the ASV experiments. Optimized square wave anodic stripping voltammetry 
parameters at the IJP-MWNT electrode surface are $30 \mathrm{~Hz}, 0.1 \mathrm{~V},-1.0 \mathrm{~V}, 0.004 \mathrm{~V}$ and $300 \mathrm{~s}$ respectively for frequency, amplitude, deposition potential, potential step, and deposition time.

\section{RESULTS AND DISCUSSION}

\subsection{Surface Characterization}

The IJP-MWNT electrode surface morphology was explored by scanning electron microscope, (Fig. 2. a-b) shows the high surface area of the MWNT structure. The entirety of the electrode was searched for any of the silver track protruding through the electrode surface. The silver had to be completely covered to avoid silver becoming part of the electrode solution interface and participate in the electrochemical oxidation and reduction. The exposed silver would act as a separate electrode surface and be a cause of error in concentration calculation, as silver is known

to be a sensitive working electrode for heavy metals. ${ }^{52,53} \mathrm{We}$ did not find any silver protruding through the MWNT electrode surface, but in some instances, we have seen silver on the edges of the electrode indicating that the MWNT ink was not printed completely over the silver tracks. The flaws in the printing process were observable in the optical microscope and electrodes with defects were not used. The electrode surface was imaged with an optical microscope at $200 \mathrm{x}$ to determine the width of electrodes which was approximately $730 \mu \mathrm{m}$ and to evaluate if electrodes had silver uncovered on any edges (Fig. 3 c). An image of a 2 mm IJP-MWNT electrode is shown next to a quarter after fabrication in (Fig. 3d). 

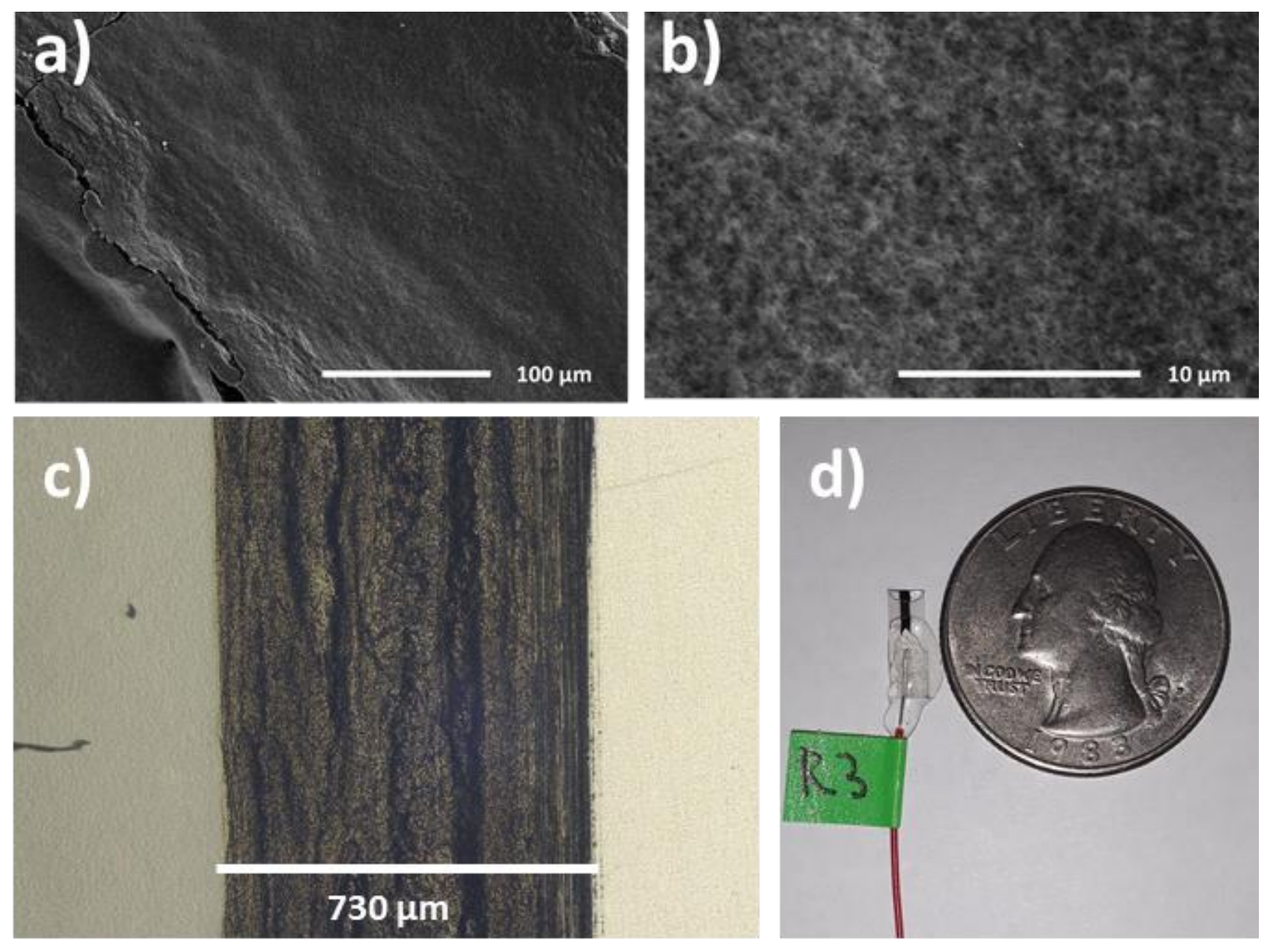

Fig.2. a) SEM images of the IJP-MWNT electrode surface at $350 \mathrm{x}, \mathrm{b}$ ) and $5000 \mathrm{x}$ magnification.

c) Optical microscope image at $200 \mathrm{x}$ magnification and d) image of $2 \mathrm{~mm}$ IJP-MWNT working electrode.

Multiwalled carbon nanotubes are known to have the $\mathrm{sp}^{2}$ form of carbon in their nanostructure. The G-band peak at $\sim 1582 \mathrm{~cm}^{-1}$ in (Fig. 3a) is a characteristic of the $\mathrm{C}-\mathrm{C}$ stretch in $\mathrm{sp}^{2}$ hybridized carbon. ${ }^{54,55}$ The D-band peak at $\sim 1334 \mathrm{~cm}^{-1}$ indicating defects in the $\mathrm{sp}^{2}$ structure which is characteristic of MWNTs is apparent as well (Fig.3. a) ${ }^{54,55}$ The D/G ratio was 1.507 , revealing that the carbon has many defects. For MWNT the D/G ratio is usually high due the large number of defects in the tubes. Intense sonication of the MWNTs that occurred during the 
dispersion procedure can cause the nanotubes to split and create more defect sites. The open ends of MWNTs are all $\mathrm{sp}^{3}$ hybridized carbon adding to the large $\mathrm{D} / \mathrm{G}$ ratio.

Cyclic voltammetry was used to determine the electrodes electroactive ability. The electrode length was varied from $2 \mathrm{~mm}$ to $20 \mathrm{~mm}$ and the effects were determined by cyclic voltammetry (Fig.3 b). All electrodes observed Nernstian electron transfer behavior for a one electron transfer process having a $\Delta \mathrm{E}_{\mathrm{p}}$ equal to $59 \mathrm{mV}$. The non-faradaic current increases with electrode length, and this was unwanted for our sensor system. We were concerned that the large non-faradaic current would interfere with the detection of low ppb concentrations of lead, and so we chose the smallest electrode length of $2 \mathrm{~mm}$ to perform the future experiments of trace metal detection. We also observed the operating potential window for the IJP-MWNT electrode to be $+0.1--0.6 \mathrm{~V}$.
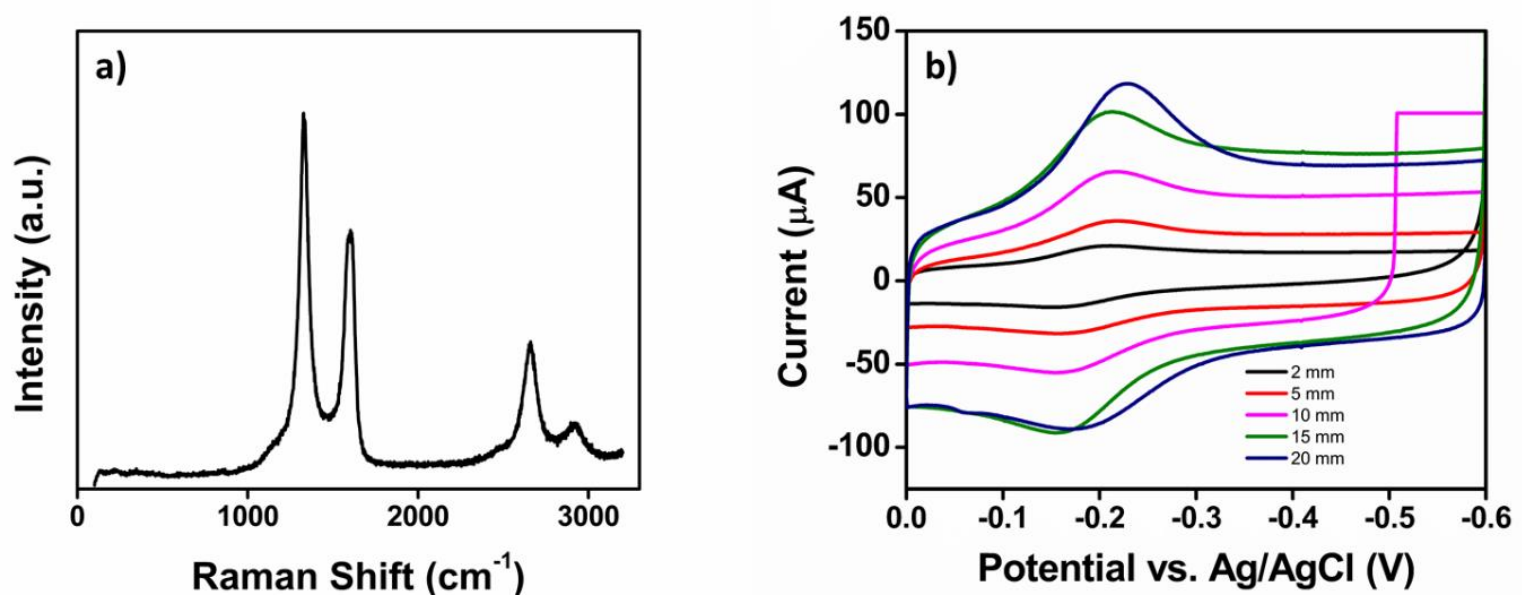

Fig. 3. a) Raman spectrum of IJP-MWNT surface using $514 \mathrm{~nm}$ wavelength laser at $100 \%$ intensity. b) Cyclic Voltammogram of $2 \mathrm{mM}$ hexaamineruthenium (III) chloride in $0.1 \mathrm{M} \mathrm{NaCl}$ at the IJP-MWNT surface with varying length of 2, 5, 10, 15, and $20 \mathrm{~mm}$ at a san rate of $50 \mathrm{mV} / \mathrm{s}$.

\subsection{IJP-MWNT Electrode Square Wave Parameters}


Before determining the LOD of the IJP-MWNT based sensor the ASV experimental parameters frequency, amplitude, deposition potential, and deposition time were optimized for the detection of lead at the IJP-MWNT electrode surface (Fig. $4 \mathrm{a}-$ d). The ASV experiments for (Fig. $4 \mathrm{a}-\mathrm{c}$ ) were performed at the IJP-MWNT electrode surface in $0.1 \mathrm{M}(\mathrm{pH}=4.3)$ with $100 \mathrm{ppb} \mathrm{Pb}^{2+}$, using parameters of $30 \mathrm{~Hz}, 100 \mathrm{mV},-1.0 \mathrm{~V}, 4 \mathrm{mV}$, and $120 \mathrm{~s}$ for the frequency, amplitude, deposition potential, potential step and deposition time respectively. The results of the ASV experiments shown in (Fig 4. d) were obtained in $0.1 \mathrm{M}$ acetate buffer $(\mathrm{pH}=4.3)$ with $50 \mathrm{ppb}$ $\mathrm{Pb}^{2+}$ using the same parameters. Each parameter experiment was performed with a single IJPMWNT electrode and done in triplicate $(\mathrm{n}=3)$.

The frequency peak height plot (Fig. 4a) shows $5 \mathrm{~Hz}$ as having the largest peak current, but that did not correlate to better detection at low ppb lead concentrations. The peak shape and detection at low ppb levels of lead were also considered when choosing the optimized frequency parameter of $30 \mathrm{~Hz}$. The peak height increased linearly with amplitude until $125 \mathrm{mV}$ were in the voltammograms the peaks lost their shape and started to become broadened. $100 \mathrm{mV}$ amplitude was the best compromise between peak shape and height. The IJP-MWNT electrode did not start detecting lead until a deposition potential of $-0.6 \mathrm{~V}$ was applied. The stripping potential of lead at the IJP-MWNT electrode was $-380 \mathrm{mV}$, and no pre-deposition potential reduction or oxidation was noticed at the electrode surface. The peak height increased with deposition potential until $-1.0 \mathrm{~V}$, then a constant decrease was observed with increased deposition potential. The increase in deposition potential caused bubbles to be formed on the electrode surface which is indicative of hydrogen reduction into hydrogen gas. The evolution of hydrogen can block the surface area of the electrode, leading to a decrease in deposited heavy metal ions. We chose -1.0 $\mathrm{V}$ as the deposition potential as no bubbles were observed at this potential. The deposition time 
was varied from $30 \mathrm{~s}$ to $900 \mathrm{~s}$ with the increase in peak height with the addition of time. At higher deposition times (past $300 \mathrm{~s}$ ) a second peak was observed at a potential of $-492 \mathrm{mV}$. The time of $300 \mathrm{~s}$ was then chosen for the preconcentration time to maintain a single peak.
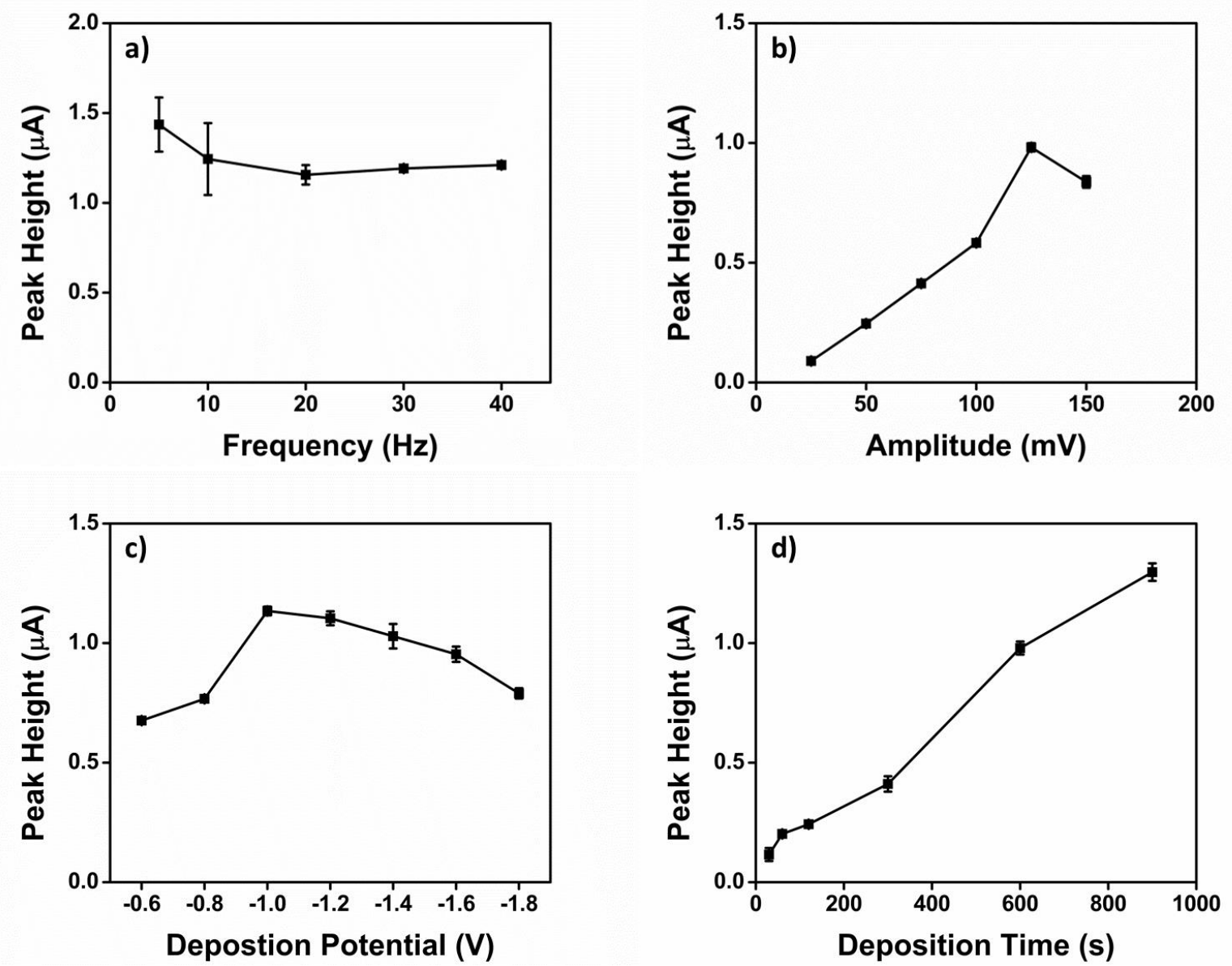

Fig. 4. The optimization of the ASV parameters at the IJP-MWNT electrode surface a) frequency, b) amplitude, c) deposition potential, and d) deposition time. Plots $(a-c)$ are the peak

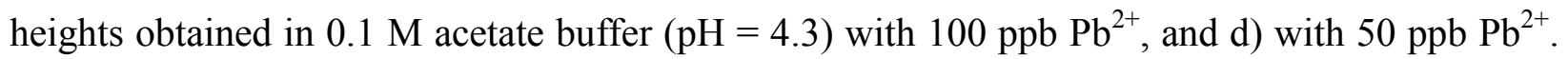
$(\mathrm{n}=3)$

\subsection{Calibration Curve in Acetate Buffer}

The IJP-MWNT electrode was employed in $0.1 \mathrm{M}$ acetate buffer $(\mathrm{pH}=4.3)$ using the optimized ASV parameters to detect $\mathrm{Pb}^{2+}$ and a calibration curve was constructed. For each concentration 
the experiment was repeated 3 times $(n=3)$ and for the lowest concentration 5 ppb the experiment was repeated 7 times $(n=7)$ to obtain standard deviation. The calibration curve was completed with a single IJP-MWNT electrode. Our results in (Fig. 5b) reveal the sensitivity of the IJP-MWNT based sensor for $\mathrm{Pb}^{2+}$ in acetate buffer is $20.15 \mathrm{nA} / \mathrm{ppb}$, with a linear range of 5 $50 \mathrm{ppb}$. The correlation equation is $\mathrm{I}(\mu \mathrm{A})=0.02015\left[\mathrm{~Pb}^{2+}(\mathrm{ppb})\right]+0.19089\left(\mathrm{R}^{2}=0.98235\right)($ Fig5 b). The LOD was calculated using the $(3 \sigma \mathrm{n}=7)$ method and is $1.632 \mathrm{ppb}$ for $\mathrm{Pb}^{2+}$. This LOD is well below the EPA's and WHO MCL of 15 and $10 \mathrm{ppb}$ for lead respectively.
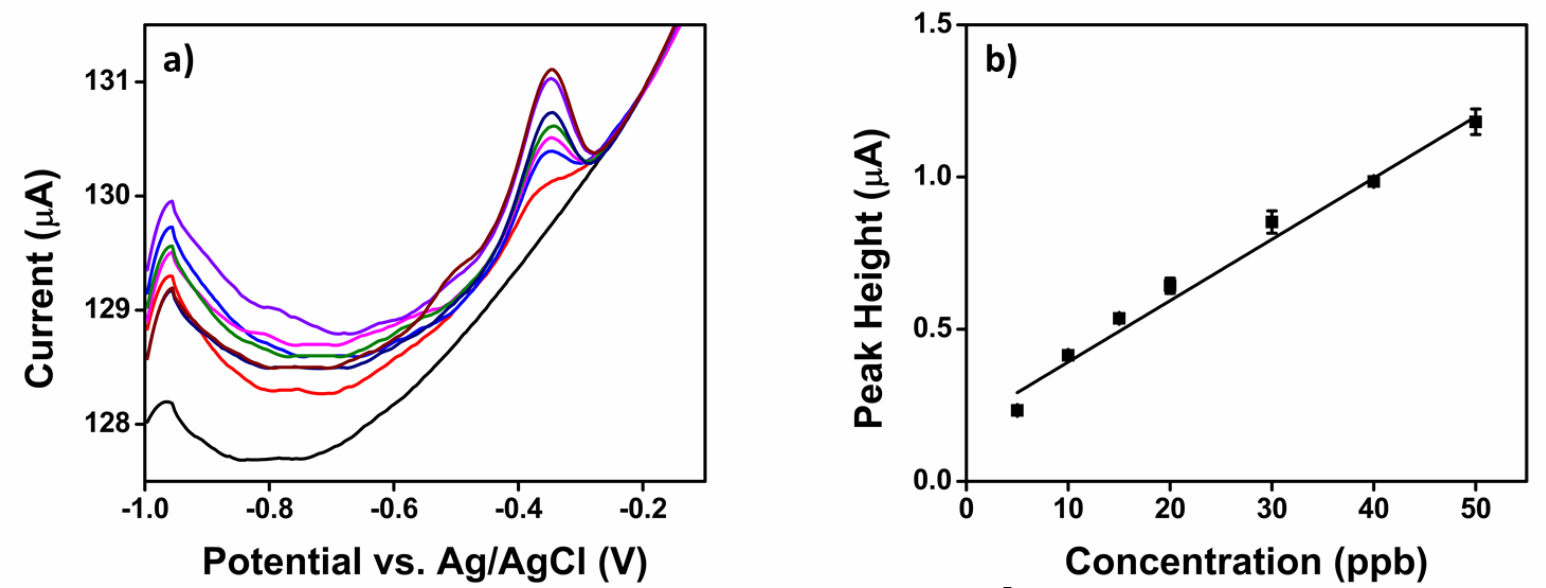

Fig. 5. a) ASVs with $0,5,10,15,25,35,50$, and $65 \mathrm{ppb} \mathrm{Pb}^{2+}$, in $0.1 \mathrm{M}$ acetate buffer $(\mathrm{pH}=4.3)$ at IJP-MWNT electrode surface. b) Calibration curve for $\mathrm{Pb}^{2+}$ in acetate buffer.

\subsection{Interference Study with $\mathrm{Cu}^{2+}$ and $\mathrm{Cd}^{2+}$}

To determine the effectiveness of the IJP-MWNT electrode in drinking water we wanted to determine the effect of other common metals that are reported in drinking water. We decided that $\mathrm{Cu}^{2+}$, and $\mathrm{Cd}^{2+}$ ions would show the applicability of our electrode. Copper, likely to be present in drinking water sources that are transported by copper plumbing. Cadmium was chosen as the redox potential of $\mathrm{Cd}^{2+}$ is very close to that of $\mathrm{Pb}^{2+}$ and is also another toxic heavy metal of 
interest. The effects of $\mathrm{Cu}^{2+}$ and $\mathrm{Cd}^{2+}$ on the detection of trace amounts of $\mathrm{Pb}^{2+}$ can be seen in (Fig. 6). $\mathrm{Cd}^{2+}$ does not have detrimental effect on the detection of $10 \mathrm{ppb}^{\mathrm{Pb}^{2+}}$ at low concentrations but at high levels the peak can diminish up to $41.62 \%$ with the addition of 200 ppb $\mathrm{Cd}^{2+}$. The loss in peak height is not due the peaks overlapping as the $\mathrm{Cd}^{0}$ stripping peak is at $-716 \mathrm{mV}$. The two metal ions are in competition for active binding sites on the electrodes surface. The effect of the peak diminishing plateaus at $100 \mathrm{ppb}$ which is an extremely high level of cadmium and is even unlikely to be seen in at drinking water sources as cadmium's MCL determined by the EPA is 5 ppb. ${ }^{4,56}$

The copper interference caused a much larger effect on the stripping peak for lead even though the $\mathrm{Cu}^{2+}$ stripping peak potential at $+32.0 \mathrm{mV}$ is over $300 \mathrm{mV}$ away from the lead stripping peak. The effect was substantial at low copper concentration of $10 \mathrm{ppb}$ having a decrease in lead peak height by $37.5 \%$ (Fig 6.d). A reason copper had a more profound effect compared to that of cadmium, on the lead stripping peak may be since copper is reduced to the electrode surface first and stripped off last. This may give rise to lead reducing on copper and stripping from copper which will change the binging energy to the electrode and change the potential at which lead will oxidized back into solution. This effect can cause multiple peaks or shoulders in peaks mainly at higher concentration of lead or cause a broadening of the peak at lower concentrations. ${ }^{50}$ Copper is more problematic in that the MLC determined by the EPA for copper is $1.3 \mathrm{ppm}$. The negative effect of copper on the IJP-MWNT electrodes ability to detect lead plateaus at $100 \mathrm{ppb}$ of $\mathrm{Cu}^{2+}$, and the lead peak can still be observed. 

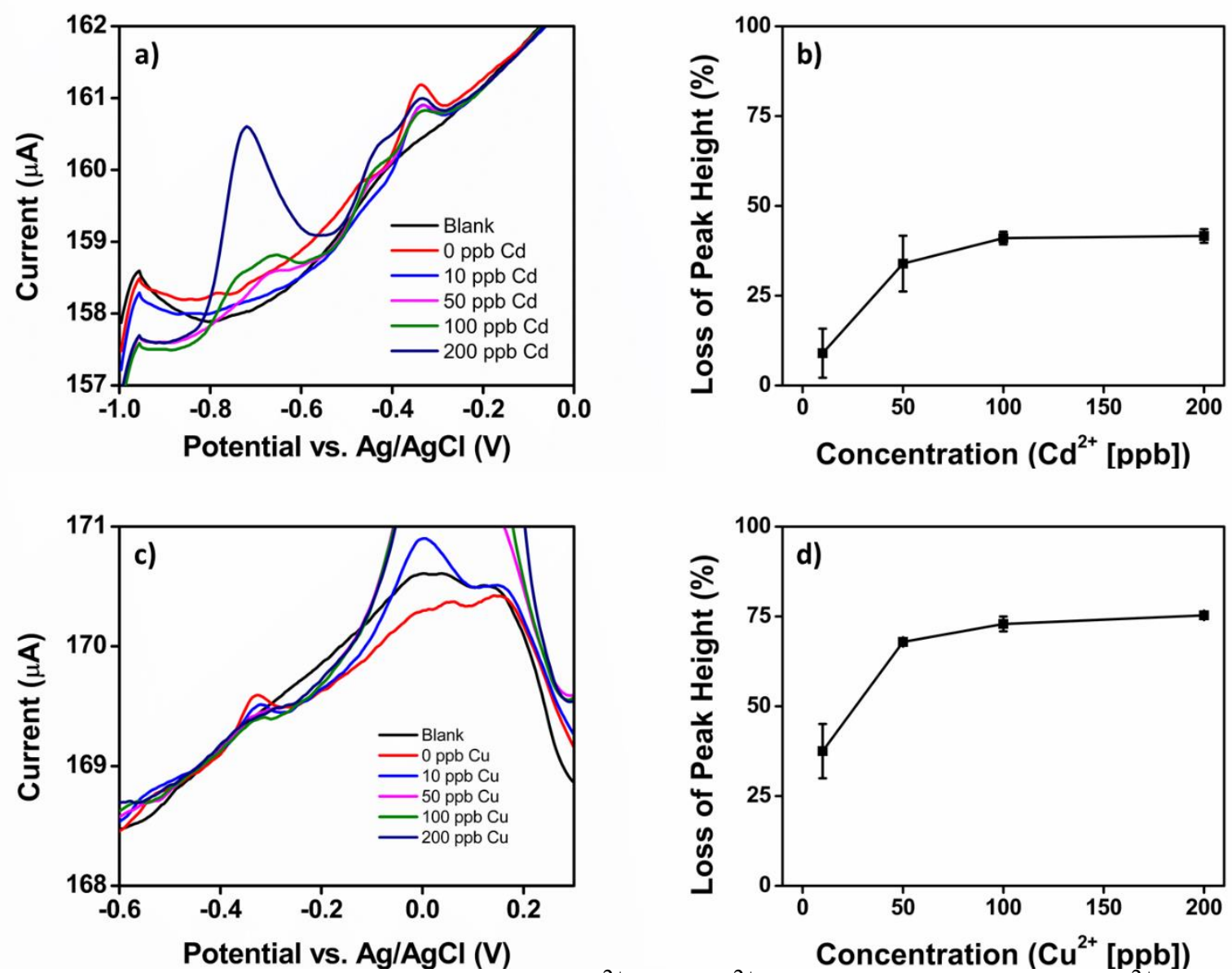

Fig. 6. Interference study of the effect of $\mathrm{Cd}^{2+}$ and $\mathrm{Cu}^{2+}$ ions on the detection of $\mathrm{Pb}^{2+}$. a) ASVs of $10 \mathrm{ppb} \mathrm{Pb}^{2+}$ in $0.1 \mathrm{M}$ acetate buffer $(\mathrm{pH}=4.3)$, with the sequential addition of $10,50,100$, and $200 \mathrm{ppb} \mathrm{Cd}^{2+}$ and $\mathrm{b}$ ) is the loss of peak height percentage with the addition of $\mathrm{Cd}^{2+}$. c) ASVs of $25 \mathrm{ppb} \mathrm{Pb}^{2+}$ in $0.1 \mathrm{M}$ acetate buffer $(\mathrm{pH}=4.3)$, with the sequential addition of $10,50,100$, and $200 \mathrm{ppb} \mathrm{Cu}^{2+}$ and $\mathrm{d}$ ) is the loss of peak height percentage with the addition of $\mathrm{Cu}^{2+}$.

\subsection{Analysis of Drinking Water}

To prove the applicability of the IJP-MWNT sensor platform to detect lead in real drinking water samples we collected potable tap water (Crosley Tower, University of Cincinnati, OH, Sept 1, 2019) and determined $\mathrm{Pb}^{2+}$ using the IJP-MWNT sensor platform. The sample was collected into 
a 1 L high-density polyethylene (HDPE) bottle for storage. The ASV experiments were performed in the tap water sample without the addition of supporting electrolyte or $\mathrm{pH}$ buffer solutions. The $\mathrm{pH}$ and conductivity were measured at 7.44 and $415.38 \mu \mathrm{S}$ respectively compared to the $\mathrm{pH}$ and conductivity of the $0.1 \mathrm{M}$ acetate buffer of 4.3 and $2666.61 \mu \mathrm{S}$ respectively.

The calibration curve was collected using the IJP-MWNT sensor by employing ASV in 15 ppb to $70 \mathrm{ppb} \mathrm{Pb}^{2+}$ in Cincinnati tap water using the optimized parameters. Each concentration was repeated $3(\mathrm{n}=3)$ times and the lowest concentration $15 \mathrm{ppb}$ of $\mathrm{Pb}^{2+}$ was repeated 7 times to obtain standard deviation $(\mathrm{n}=7)$. The sensitivity of the IJP-MWNT electrode in a real drinking water sample for $\mathrm{Pb}^{2+}$ is $2.654 \mathrm{nA} / \mathrm{ppb}$ (Fig 7b). The correlation equation is $\mathrm{I}(\mathrm{nA})=2.654\left[\mathrm{~Pb}^{2+}\right.$ $(\mathrm{ppb})]-12.57\left(\mathrm{R}^{2}=0.98752\right)$. The LOD for $\mathrm{Pb}^{2+}=1.269 \mathrm{ppb}$ which was calculated using the $(3 \sigma \mathrm{n}=7)$ method. The LOD of the IJP-MWNT sensor platform is low enough to be used at POC.
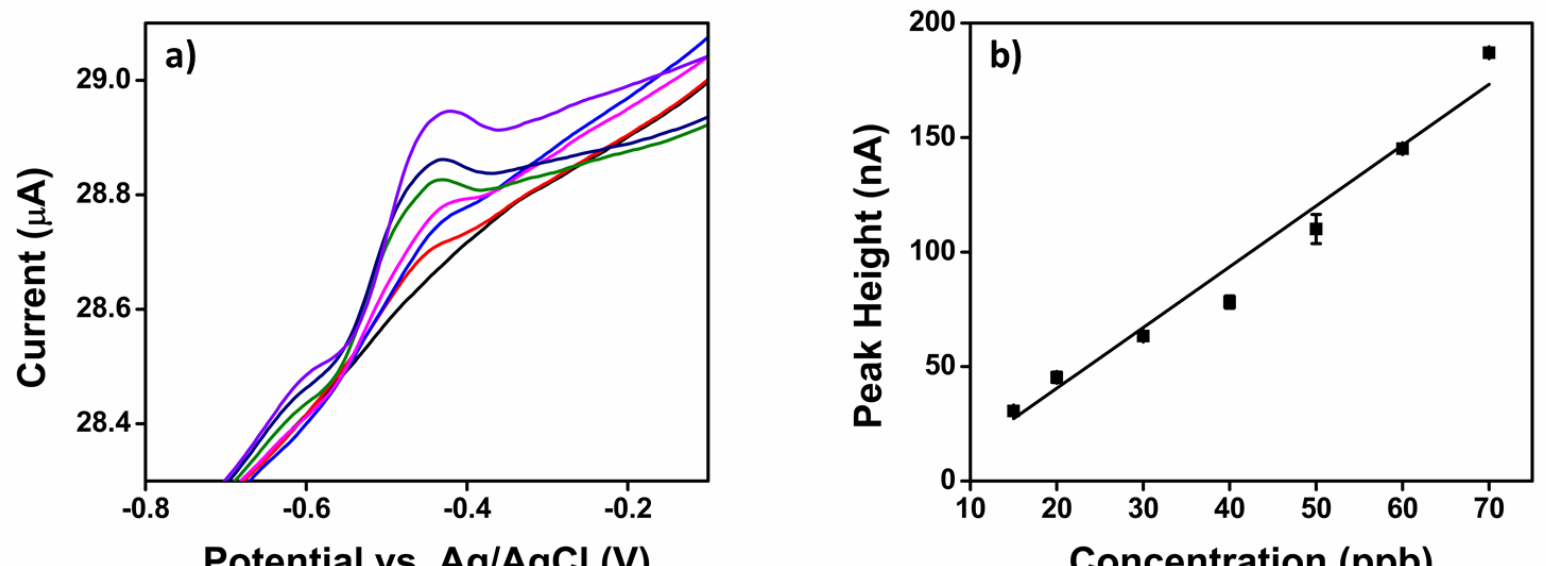

Fig. 7. a) ASVs of $\mathrm{Pb}^{2+}$ at $15,20,40,50,60$, and $70 \mathrm{ppb}$, in Cincinnati tap water $(\mathrm{pH}=7.44)$ at the IJP-MWNT electrode surface. b) Calibration curve for $\mathrm{Pb}^{2+}$ in unaltered potable tap water.

\section{Conclusion}


An inkjet printed MWNT electrode was developed as a sensor for the detection of the toxic heavy metal $\mathrm{Pb}^{2+}$ in drinking water samples. The electrode was shown to be sensitive at low ppb concentrations with a LOD of $1.26 \mathrm{ppb}\left(\mathrm{R}^{2}=0.98752\right)$ in real drinking water samples. The IJPMWNT is reproducible between electrodes, have a long lifetime of over 50 ASV experiments with high ppb levels of lead, and the electrode is environmentally friendly to dispose of. The electrode can be easily and quickly be fabricated without modifications or in-situ additives needed, which makes up-scale production a feasible option. The sensor has been shown to perform well in an environmental sample (Cincinnati tap water) without any sample preparation or changes. The interference of meatal ions copper and cadmium on the lead detection was studied and while copper had a substantial effect on the peak the sensor was still able to detect low ppb levels of $\mathrm{Pb}^{2+}$. We present this IJP-MWNT electrode as a viable POC sensor at consumer homes, schools, and workplaces for the trace detection of lead in drinking water sources. 


\section{References}

1. Boeckx, R. L. Lead Poisoning in Children. Chem. Anal. Soc. Am. Chem. 58, 274-288 (1986).

2. Birdsall, R. E. et al. Effects of Lead and Mercury on the Blood Proteome of Children. J. Proteome Res. 9, 4443-4453 (2010).

3. Cabral, M. et al. Effects of environmental cadmium and lead exposure on adults neighboring a discharge : Evidences of adverse health effects e. Environ. Pollut. 206, 247255 (2015).

4. US EPA. National Primary Drinking Water Regulations for Lead and Copper: ShortTerm Regulatory Revisions and Clarifications; Final Rule. Fed. Regist. 72, 1-40 (2007).

5. World Health Organization (WHO). Testing a self-medication hypothesis in battered women. Diss. Abstr. Int. Sect. B Sci. Eng. 57, 6562 (2011).

6. Doré, E., Deshommes, E., Andrews, R. C., Nour, S. \& Prévost, M. Sampling in schools and large institutional buildings : Implications for regulations, exposure and management of lead and copper. Water Res. 140, 110-122 (2018).

7. Lee, W. L., Jia, J. \& Bao, Y. Identifying the Gaps in Practice for Combating Lead in Drinking Water in Hong Kong. Int. J. Environmnetal Res. Public Heal. 13, (2016).

8. Le Bot, B., Lucas, J., Lacroix, F. \& Glorennec, P. Exposure of children to metals via tap water ingestion at home : Contamination and exposure data from a nationwide survey in France. Evironmental Int. 94, 500-507 (2016).

9. Ng, D., Liu, S. \& Lin, Y. Lead as a legendary pollutant with emerging concern: Survey of lead in tap water in an old campus building using four sampling methods. Sci. Total Envirornment 636, 1510-1516 (2018).

10. Olson, T. M. et al. Forensic Estimates of Lead Release from Lead Service Lines during the Water Crisis in Flint, Michigan. (2017). doi:10.1021/acs.estlett.7b00226

11. Edzwald, J. K. \& American Water Works Association. Water quality \& treatment : a handbook on drinking water (6th ed). (McGraw-Hill, New York, 2011).

12. Cartier, C., Nour, S., Richer, B., Deshommes, E. \& Prévost, M. Impact of water treatment on the contribution of faucets to dissolved and particulate lead release at the tap. Water Res. 46, 5205-5216 (2012).

13. Chałupniak, A. \& Merkoçi, A. Graphene Oxide - Poly ( dimethylsiloxane ) -Based Labon-a-Chip Platform for Heavy-Metals Preconcentration and Electrochemical Detection. ACS Appl. Mater. Interfaces 9, 44766-44775 (2017).

14. Lin, W., Li, Z. \& Burns, M. A. A Drinking Water Sensor for Lead and Other Heavy Metals. Anal. Chem. 89, 8748-8756 (2017).

15. Xuan, X., Hossain, F. \& Park, J. Y. A Fully Integrated and Miniaturized Heavy-metaldetection Sensor Based on Micro-patterned Reduced Graphene Oxide. Nat. Publ. Gr. 1-8 
(2016). doi:10.1038/srep33125

16. Kang, W. et al. Determination of Lead with a Copper-Based Electrochemical Sensor. Anal. Chem. 89, 3345-3352 (2017).

17. Baldo, M. A., Daniele, S., Ciani, I., Bragato, C. \& Wang, J. Remote stripping analysis of lead and copper by a mercury-coated platinum microelectrode. Electroanalysis 16, 360366 (2004).

18. Batley, G. E. Electroanalytical Techniques For The Determination of Heavy Metals In Seawater. Mar. Chem. 12, 107-117 (1983).

19. Armstrong, K. C., Tatum, C. E., Dansby-Sparks, R. N., Chambers, J. Q. \& Xue, Z. L. Individual and simultaneous determination of lead, cadmium, and zinc by anodic stripping voltammetry at a bismuth bulk electrode. Talanta 82, 675-680 (2010).

20. Jia, J., Cao, L. \& Wang, Z. Nafion/poly(sodium 4-styrenesulfonate) mixed coating modified bismuth film electrode for the determination of trace metals by anodic stripping voltammetry. Electroanalysis 19, 1845-1849 (2007).

21. Saturno, J., Valera, D., Carrero, H. \& Fernández, L. Electroanalytical detection of Pb, Cd and traces of $\mathrm{Cr}$ at micro/nano-structured bismuth film electrodes. Sensors Actuators, $B$ Chem. 159, 92-96 (2011).

22. Injang, U. et al. Determination of trace heavy metals in herbs by sequential injection analysis-anodic stripping voltammetry using screen-printed carbon nanotubes electrodes. Anal. Chim. Acta 668, 54-60 (2010).

23. Bobrowski, A., Putek, M. \& Zarebski, J. Antimony Film Electrode Prepared In Situ in Hydrogen Potassium Tartrate in Anodic Stripping Voltammetric Trace Detection of $\mathrm{Cd}(\mathrm{II}), \mathrm{Pb}(\mathrm{II}), \mathrm{Zn}(\mathrm{II}), \mathrm{Tl}(\mathrm{I}), \mathrm{In}(\mathrm{III})$ and Cu(II). Electroanalysis 24, 1071-1078 (2012).

24. McGaw, E. A. \& Swain, G. M. A comparison of boron-doped diamond thin-film and Hgcoated glassy carbon electrodes for anodic stripping voltammetric determination of heavy metal ions in aqueous media. Anal. Chim. Acta 575, 180-189 (2006).

25. Huang, H., Chen, T., Liu, X. \& Ma, H. Ultrasensitive and simultaneous detection of heavy metal ions based on three-dimensional graphene-carbon nanotubes hybrid electrode materials. Anal. Chim. Acta 852, 45-54 (2014).

26. Yue, W. et al. Anodic Stripping Voltammetry of Heavy Metals on a Metal Catalyst Free Carbon Nanotube Electrode. Electroanalysis 24, 1039-1046 (2012).

27. Zhao, D. et al. Simultaneous Detection of Heavy Metals by Anodic Stripping Voltammetry Using Carbon Nanotube Thread. Electroanalysis 26, 488-496 (2014).

28. Guo, X., Yun, Y., Shanov, V. N., Halsall, H. B. \& Heineman, W. R. Determination of trace metals by anodic stripping voltammetry using a carbon nanotube tower electrode. Electroanalysis 23, 1252-1259 (2011).

29. Zhao, D. et al. Electrospun Carbon Nanofiber Modified Electrodes for Stripping Voltammetry. Anal. Chem. 87, 9315-9321 (2015). 
30. Saban, S. B. \& Darling, R. B. Multi-element heavy metal ion sensors for aqueous solutions. Sensors Actuators, B Chem. 61, 128-137 (1999).

31. Xie, F. et al. Carbon-based nanomaterials - A promising electrochemical sensor toward persistent toxic substance. TrAC Trends Anal. Chem. 119, 115624 (2019).

32. Jewell, E., Philip, B. \& Greenwood, P. Improved manufacturing performance of screen printed carbon electrodes through material formulation. Biosensors (2016). doi:10.3390/bios6030030

33. Wang, J. \& Tian, B. Screen-Printed Stripping Voltammetric/Potentiometric Electrodes for Decentralized Testing of Trace Lead. Anal. Chem. 64, 1706-1709 (1992).

34. Niu, X., Zhao, H. \& Lan, M. Disposable Screen-printed Bismuth Electrode Modified with Multi-walled Carbon Nanotubes for Electrochemical Stripping Measurements. Anal. Sci. 27, 1237-1241 (2011).

35. Wang, J., Lu, J., Hocevar, S. B., Farias, P. A. M. \& Ogorevc, B. Bismuth-coated carbon electrodes for anodic stripping voltammetry. Anal. Chem. 72, 3218-3222 (2000).

36. Masawat, P., Liawruangrath, S. \& Slater, J. M. Flow injection measurement of lead using mercury-free disposable gold-sputtered screen-printed carbon electrodes ( SPCE ). Sensors Actuators B 91, 52-59 (2003).

37. Morton, J., Havens, N., Mugweru, A. \& Wanekaya, A. K. Detection of trace heavy metal ions using carbon nanotube modified electrodes. Electroanalysis 21, 1597-1603 (2009).

38. Cummins, G. \& Desmulliez, M. P. Y. Inkjet printing of conductive materials: A review. Circuit World 38, 193-213 (2012).

39. Dong, S. et al. Inkjet Printing Synthesis of Sandwiched Structured Ionic Liquid- Carbon Nanotube-Graphene Film: Toward Disposable Electrode for Sensitive Heavy Metal Detection in Environmental Water Samples. Ind. Eng. Chem. Res. 56, 1696-1703 (2017).

40. Teerapanich, P., Tay, M., Myint, Z., Joseph, C. M. \& Hornyak, G. L. Development and Improvement of Carbon Nanotube-Based Ammonia Gas Sensors Using Ink-Jet Printed Interdigitated Electrodes. IEEE Trans. Nanotechnol. 12, 255-262 (2013).

41. Huang, L. et al. Sensors and Actuators B : Chemical A novel paper-based flexible ammonia gas sensor via silver and SWNT-PABS inkjet printing. Sensors Actuators $B$. Chem. 197, 308-313 (2014).

42. Lee, H. \& Lee, S. Simple fabrication method of flexible carbon nanotube electrodes using inkjet and transfer printing methods for dopamine detection. J. Taiwan Inst. Chem. Eng. 92, 63-71 (2018).

43. Schneider, M., Türke, A., Fischer, W. \& Kilmartin, P. A. Determination of the wine preservative sulphur dioxide with cyclic voltammetry using inkjet printed electrodes. Food Chem. 159, 428-432 (2014).

44. Torres-Canas, F. et al. Morphology and anisotropy of thin conductive inkjet printed lines of single-walled carbon nanotubes. Mater. Res. Express 4, 035037 (2017). 
45. Torres-canas, F. et al. Inkjet Printing of Latex-Based High-Energy Microcapacitors. 1901884, 1-9 (2019).

46. Sowers, T. et al. Solution Properties of Single-Walled Carbon Nanotubes. Science (80-. ). 282, 95-98 (1998).

47. Peigney, A., Laurent, C., Flahaut, E., Bacsa, R. R. \& Rousset, A. Specific surface area of carbon nanotubes and bundles of carbon nanotubes. Carbon N. Y. 39, 507-514 (2001).

48. Wang, J. \& Musameh, M. Carbon nanotube screen-printed electrochemical sensors. $R$. Soc. Chem. Anal. 129, 1-2 (2004).

49. Lima, A. P. et al. Investigation on acid functionalization of double-walled carbon nanotubes of different lengths on the development of amperometric sensors. Electrochim. Acta 299, 762-771 (2019).

50. Honeychurch, K. C., Hart, J. P. \& Cowell, D. C. Voltammetric behavior and trace determination of lead at a mercury-free screen-printed carbon electrode. Electroanalysis 12, 171-177 (2000).

51. Osteryoung, J. G. \& A., O. R. Square-wave voltammetry. Anal. Chem. 57, 101-110 (1985).

52. Baś, B. The renovated silver ring electrode. Electrochem. commun. 10, 156-160 (2008).

53. Sivasubramanian, R. \& Sangaranarayanan, M. V. Detection of lead ions in picomolar concentration range using underpotential deposition on silver nanoparticles-deposited glassy carbon electrodes. Talanta 85, 2142-2147 (2011).

54. Cooper, C. A., Young, R. J. \& Halsall, M. Investigation into the deformation of carbon nanotubes and their composites through the use of Raman spectroscopy. Compos. Part A Appl. Sci. Manuf. (2001). doi:10.1016/S1359-835X(00)00107-X

55. Dresselhaus, M. S., Jorio, A., Hofmann, M., Dresselhaus, G. \& Saito, R. Perspectives on carbon nanotubes and graphene Raman spectroscopy. Nano Lett. 10, 751-758 (2010).

56. US EPA, O. National Primary Drinking Water Regulations. 